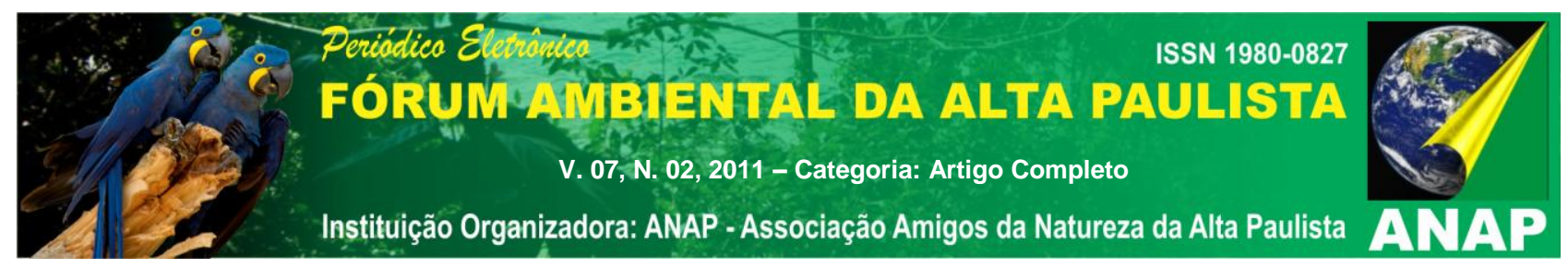

\title{
ESTUDO COMPARATIVO DAS VAZÕES DOS RIOS AGUAPEÍ E PEIXE
}

\section{Lucinete Ferreira de Andrade ${ }^{1}$}

\section{Paulo Cesar Rocha ${ }^{2}$}

RESUMO: O presente trabalho foi desenvolvido com base em estudos de caso, buscando identificar possíveis fatores de influência na variabilidade das vazões médias dos rios Aguapeí e Peixe no Oeste do Estado de São Paulo. Este trabalho se justifica por ser parte de uma pesquisa maior que engloba o estudo do comportamento hidrológico das referidas bacias como contribuição ao gerenciamento de recursos hídricos, uma vez que é iminente a implementação da política de cobrança pelo uso desses recursos na área pesquisada. O estudo está baseado no correlacionamento de dados da variabilidade de fluxos fluviométricos, fenômenos cíclicos de El Niño e outras influências advindas de fatores climáticos e uso da terra. Os dados hidrológicos foram obtidos das estações fluviométricas nas bacias hidrográficas dos rios Aguapeí e Peixe. Os resultados apresentados mostram 3 períodos distintos quanto aos desvios médios para as duas bacias. Comparando-se as duas bacias, pode-se verificar que, embora as duas bacias hidrográficas estejam contidas na mesma área geográfica, possíveis diferenças de uso da terra possam contribuir para as variações.

Palavras chave: bacias hidrográficas aguapeí e peixe. desvios médios.vazão.

\section{INTRODUÇÃO}

Este trabalho foi desenvolvido a partir de série histórica de dados hidrológicos secundários obtidos através de sítios eletrônicos de órgãos públicos como Agência

\footnotetext{
${ }^{1}$ Licenciada em Geografia, Unesp - Campus Presidente Prudente. lucineteferreira@gmail.com

${ }^{2}$ Profo Dro , Departamento de Geografia, Unesp - Campus Presidente Prudente. pcrocha@fct.unesp.br
} 


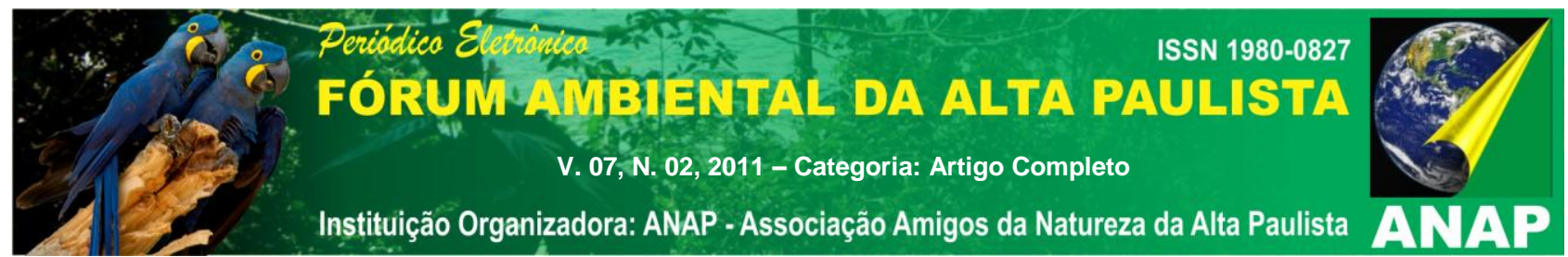

Nacional de Águas (ANA) $)^{3}$ e Sistema Integrado de Gerenciamento de Recursos Hídricos do Estado de São Paulo (SIGRH) ${ }^{4}$.

O entendimento da dinâmica do sistema hidrológico, incluindo-se o regime de fluxos fluviais nas bacias hidrográficas é de grande importância para a gestão e gerenciamento dos recursos hídricos e ambientais. A importância da gestão e do gerenciamento dos recursos hídricos está na elaboração de planos e atividades voltadas ao controle da utilização das águas.

Desse modo torna-se importante a abordagem de temas com relevância no conjunto dos processos hidrológicos, e da gestão dos recursos hídricos, uma vez que o cerne do debate é o recorte territorial da própria bacia hidrográfica e os elementos que a compõem.

Para tanto, faz-se necessário elucidar a definição da bacia hidrográfica que, de acordo com Villela e Mattos (1975), define-se como o lugar onde o ciclo hidrológico é facilmente observado, pois logo que a precipitação atinge o solo, parte da água se infiltra, por conta de depressões no terreno, uma pequena parcela da água é acumulada em superfície - tal fato se dá quando da saturação do solo e outra parte é evaporada mesmo atingindo o curso de água em pleno escoamento, esta continua sofrendo o processo de evaporação, claro que em quantidades mais desprezíveis, sendo assim, desconsideradas.

De acordo com a Lei 9433 de $1997^{5}$, é atribuição dos Comitês de Bacias Hidrográficas, articular e reunir diversos agentes para aprovação de planos em torno desse bem tão essencial e, inclusive implementar políticas de uso, tais como a cobrança pelo uso da água, incentivando usos mais conscientes.

É válido ressaltar que para se implementar políticas, tais como a cobrança pelo uso, faz-se necessário prévio conhecimento acerca da situação dos recursos hídricos na

\footnotetext{
${ }^{3}$ Dados hidrológicos disponíveis em <http://hidroweb.ana.gov.br> acessado em 28 de mar de 2011.

${ }^{4}$ Dados hidrológicos disponíveis <http://www.sigrh.sp.gov.br/cgi-bin/bdhm.exe/flu> em acessado em 11 de abr de 2011 e em <http://www.sigrh.sp.gov.br/cgi-bin/bdhm.exe/plug> acessado em 25 de abr de 2011

${ }^{5}$ LEI № 9433, DE 08 DE JANEIRO DE 1997 Institui a Política Nacional de Recursos Hídricos, cria o Sistema Nacional de Gerenciamento de Recursos Hídricos, regulamenta o inciso XIX do art. 21 da Constituição Federal, e altera o art. 1ㅇ da Lei o 8.001, de 13 de março de 1990, que modificou a Lei oㅜ 7.990, de 28 de dezembro de 1989. Disponível em <http://www.aneel.gov.br/cedoc/blei19979433.pdf> acessado em 01 de set de 2011.
} 


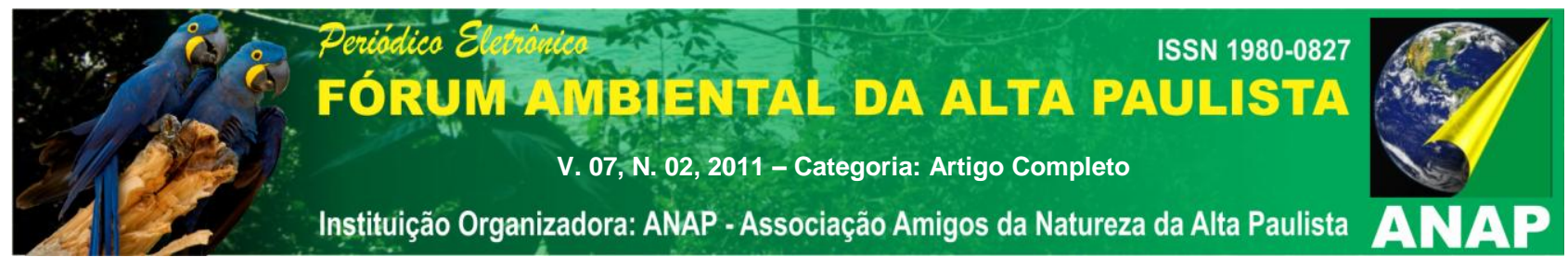

bacia hidrográfica, especificamente quantidade e volume. E tais informações são obtidas através da rede hidrométrica, que compreendem as estações de medição de vazão e cotas existentes na área onde se pretende executar o gerenciamento.

Tundisi (2003) salienta que ao gerenciamento de recursos hídricos deve-se incluir os resultados de pesquisas cientificas, com finalidade de gerar informações com significativa importância às tomadas de decisões pelos órgãos de gestão.

A partir do exposto, torna-se importante destacar que os estudos realizados a partir deste trabalho visam contribuir com as ações executadas pelos órgãos públicos ligados à gestão da água, especialmente no que tange a implementação da cobrança pelo uso da mesma.

O presente trabalho tem como objetivo apresentar o estudo comparativo das vazões nos rios Aguapeí e Peixe no Oeste do Estado de São Paulo, buscando identificar as possíveis influências do meio físico, tais como fenômenos climáticos e relações de uso e ocupação com base em estudos prévios de casos.

A área de estudos engloba duas bacias hidrográficas que compõem duas unidades de gerenciamento de recursos hídricos (UGRHI's) no Oeste paulista, respectivamente a UGRHI 20, bacia hidrográfica do rio Aguapeí e UGRHI 21, bacia hidrográfica do rio do Peixe, conforme figura 1.

\section{DISCUSSÃO TEÓRICA}

A variabilidade inter-anual dos fluxos fluviométricos representam desafios para o planejamento e gerenciamento dos recursos hídricos. Esta se dá em decorrência da variação da pluviosidade, evaporação e dos processos normalmente de escala humana ou maior como fenômenos de escala secular, inter-decadal, ciclos de El Niño e ciclos bianuais (GUETTER, 1998, p.1).

Ainda em acordo com autor supracitado, há incerteza considerável na origem e dinâmica da variabilidade secular e inter-decadal. Contudo, vários estudos indicam que a variabilidade climática nas escalas decadal a bianual provém da interação entre oceano e 


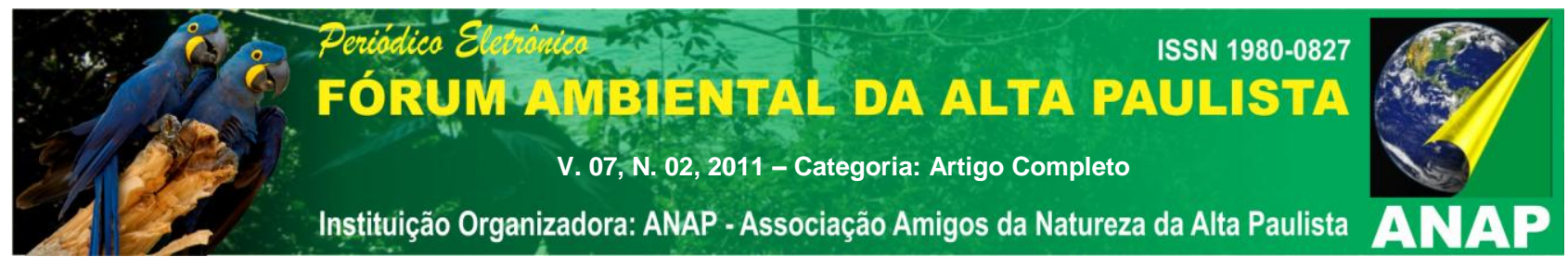

atmosfera. O El Nino/Oscilação Sul (ENOS) é o principal sistema que explica a variabilidade inter-anual com período de 3-5 anos (GUETTER, 1998, p.1).

Em estudos de casos que buscaram identificar possíveis mudanças no comportamento hidrológico com base nos fenômenos climáticos, vários estudos climáticos foram desenvolvidos em bacias hidrográficas como exemplo, Clarke et al., (2003), estudou a variabilidade temporal no regime hidrológico da bacia do rio Paraguai, e explicou que na década de 1960, a baixa vazão dos rios estava relacionada aos períodos de estiagem (dias consecutivos sem chuva). A partir de 1970, as mudanças das vazões se justificaram com aumento da precipitação pluvial (Araujo, 2011, p.75).

Andrade (2003) apud Azevedo (2006), analisou a variabilidade da precipitação pluviométrica na bacia do rio Ivaí no estado do Paraná, e constatou a influência do Trópico de Capricórnio e da Massa Tropical Continental à jusante da bacia, e à montante, a influência do relevo associada com a continentalidade que interferiam no regime de chuvas.

Rocha (2009) em estudo prévio do regime de fluxo dos rios aguapeí e peixe, bacia do alto Paraná também identificou alterações no regime hidrológico, mostrou que especialmente a partir da década de 1970, houve aumento das vazões, sendo possivelmente um dos prováveis fatores responsáveis a ocupação e uso do solo, o outro pode estar relacionado mais diretamente às alterações do regime pluviométrico.

Outros estudos procuram entender as oscilações do regime hidrológico associando-as com as anomalias climáticas provocadas pelo ENOS (EI Niño Oscilação Sul), sobretudo quanto aos altos fluxos ao El Niño, e os baixos fluxos à La Niña. Entretanto, tais abordagens tratam de uma escala maior e que pode sim, manifestar influencias na escala regional (MOLION, 2003, p.1).

O El Niño é um fenômeno de grande escala espacial gerado pelo aumento da temperatura superficial das águas no oceano pacífico, que afeta as circulações atmosféricas, gerando perturbações climáticas de âmbito global (FERREIRA e NERY, 1999, p.104), mas que pode influenciar sobremaneira o clima regional na América do sul. Em outro estudo Nery (1998), tentou demonstrar que uma das principais causas da variabilidade climática no centro sul do Brasil, principalmente a precipitação pluvial e conseqüentemente a vazão advêm da ocorrência do fenômeno El Niño. 


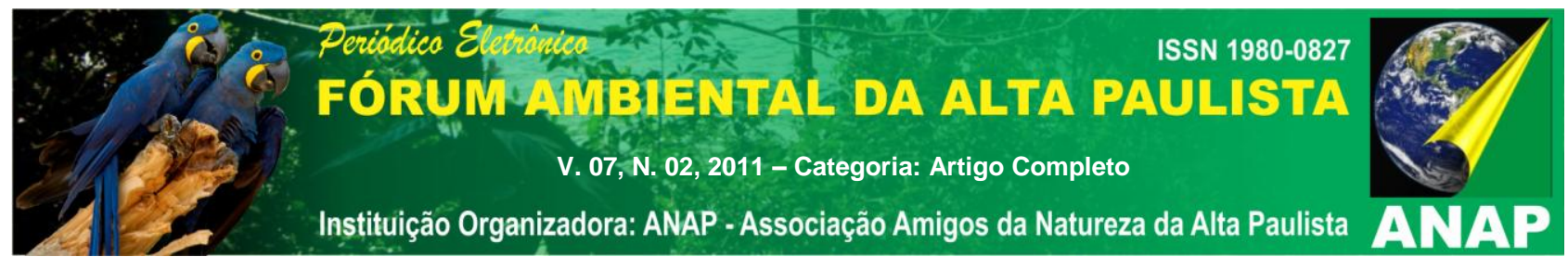

Em relação às especificidades do clima do Estado de São Paulo, Sant'Anna Neto (1995) afirma que há uma tendência natural de diminuição da pluviosidade de Leste para Oeste e de Sul para Norte, tais fatores são, no entanto, influenciados pela circulação geral da atmosfera, caracterizada pela atuação das massas tropicais (continental e marítima). Há influencia efetiva da onda de noroeste-sudeste que atinge a área do Pontal do Paranapanema e as vertentes voltadas para a calha do Rio Paraná. A pluviosidade anual é das menores do Estado, variando entre 1.100 e 1.500 mm anuais.

Em relação à caracterização geral do clima regional, Souza (2005) salienta que

Eventualmente, o clima regional tem influência das massas Tropical Atlântica (Ta), Tropical Continental (Tc) e Equatorial Continental (Ec), propiciando um período de temperaturas elevadas e altos índices pluviométricos (de outubro a março) e outro de temperaturas amenas e menores índices pluviométricos (abril a setembro) (SOUZA, 2005, p.17).

Assim, a distribuição sazonal das temperaturas na área de estudo é representada por duas estações bem definidas, em que as temperaturas médias variam entre $24^{\circ} \mathrm{C}$ e $27^{\circ} \mathrm{C}$ durante o verão e entre $19^{\circ} \mathrm{C}$ e $22^{\circ} \mathrm{C}$ durante as estações mais secas (SOUZA, 2005, p.17).

Evidentemente os fenômenos atmosféricos associados a um conjunto de fatores de uso e ocupação, orografia e cobertura vegetal influenciam diretamente o regime hidrológico, especificamente no que tange os índices pluviométricos em nível local. Em relação às chuvas no Estado de São Paulo, Sant'Anna Neto (1995) destaca que no Oeste Paulista há dois períodos sazonais muito marcantes, sendo um período quente e chuvoso entre os meses de outubro e março e outro mais ameno e seco entre os meses de abril e setembro.

\section{METODOLOGIA}

Para execução deste estudo, realizou-se inicialmente um inventário das estações fluviométricas existentes nas bacias hidrográficas dos rios Aguapeí e Peixe a partir dos sítios eletrônicos da Agencia Nacional de Águas (ANA) e do Departamento Estadual de 


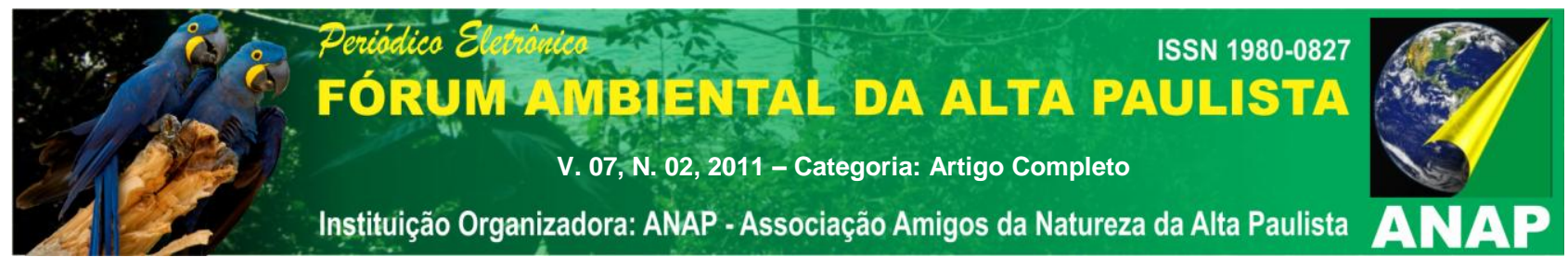

Águas de São Paulo (SIGRH), conforme mencionado anteriormente. Das estações inventariadas foram selecionadas duas para análise de dados de série histórica de vazão, sendo uma pertencente a cada bacia hidrográfica.

Foram inventariadas, dentre as duas bacias hidrográficas, um total de oito estações fluviométricas com dados hidrológicos disponíveis. Algumas estações apresentaram série de dados incompleta na ordem de dias, meses e anos, mas foi efetuado preenchimento de dados utilizando para tal o critério foi a escolha das estações de mesma área geográfica tendo características semelhantes ao meio físico, tais como a mesma região climática e geomorfológica. Os dados foram estimados com base estatística a partir de correlacionamento de dados, estabelecido para índice de correlação $R^{2}$ maior que 0,7 , através da regressão linear simples, entre estações da mesma área geográfica, conforme proposto por Poff et al. (1997).

Posteriormente ao preenchimento dos dados de vazão, foram calculadas as medias anual e mensal, pois através dos gráficos gerados foi possível identificar os possíveis períodos hidrológicos (número de anos para cada período hidrológico) de uma estação em cada bacia, possibilitando apontar períodos mais longos e mais curtos, a fim de obter o reconhecimento da variação do regime hidrológico. Para tal foi calculado o desvio médio das vazões médias anuais através do software Excel $^{\circledR}$, conforme apresentado na tabela1.

\section{RESULTADOS E DISCUSSÃO}

A bacia hidrográfica do Rio Aguapeí possui área de drenagem de $13.196 \mathrm{~km}^{2}$, limitando-se ao Norte com a Bacia do Rio Tietê, a Oeste com o Estado do Mato Grosso do Sul, tendo como divisa o Rio Paraná, a Leste seu limite é a Serra dos Agudos e ao Sul encontra-se com a Bacia do Rio do Peixe. Esta possui extensão aproximada de $420 \mathrm{~km}$ até sua foz no Rio Paraná, a uma altitude de 260 metros (SÃO PAULO, 2011).

\footnotetext{
${ }^{6}$ Informações referentes à caracterização das bacias hidrográficas em estudo estão disponíveis em < http://www.sigrh.sp.gov.br/cgi-
} 


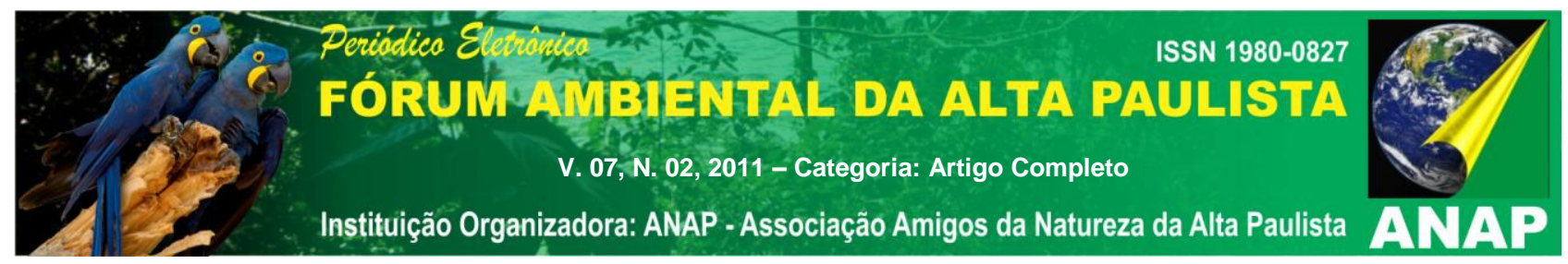

A área de drenagem da Bacia do Rio do Peixe possui 10.769 km², limita-se com a Bacia do Rio Aguapeí ao Norte, ao Sul com a Bacia do Rio Paranapanema, a Oeste com o Rio Paraná e a Leste com a Serra dos Agudos e a Serra do Mirante (SÃO PAULO, 2011), figura 1.

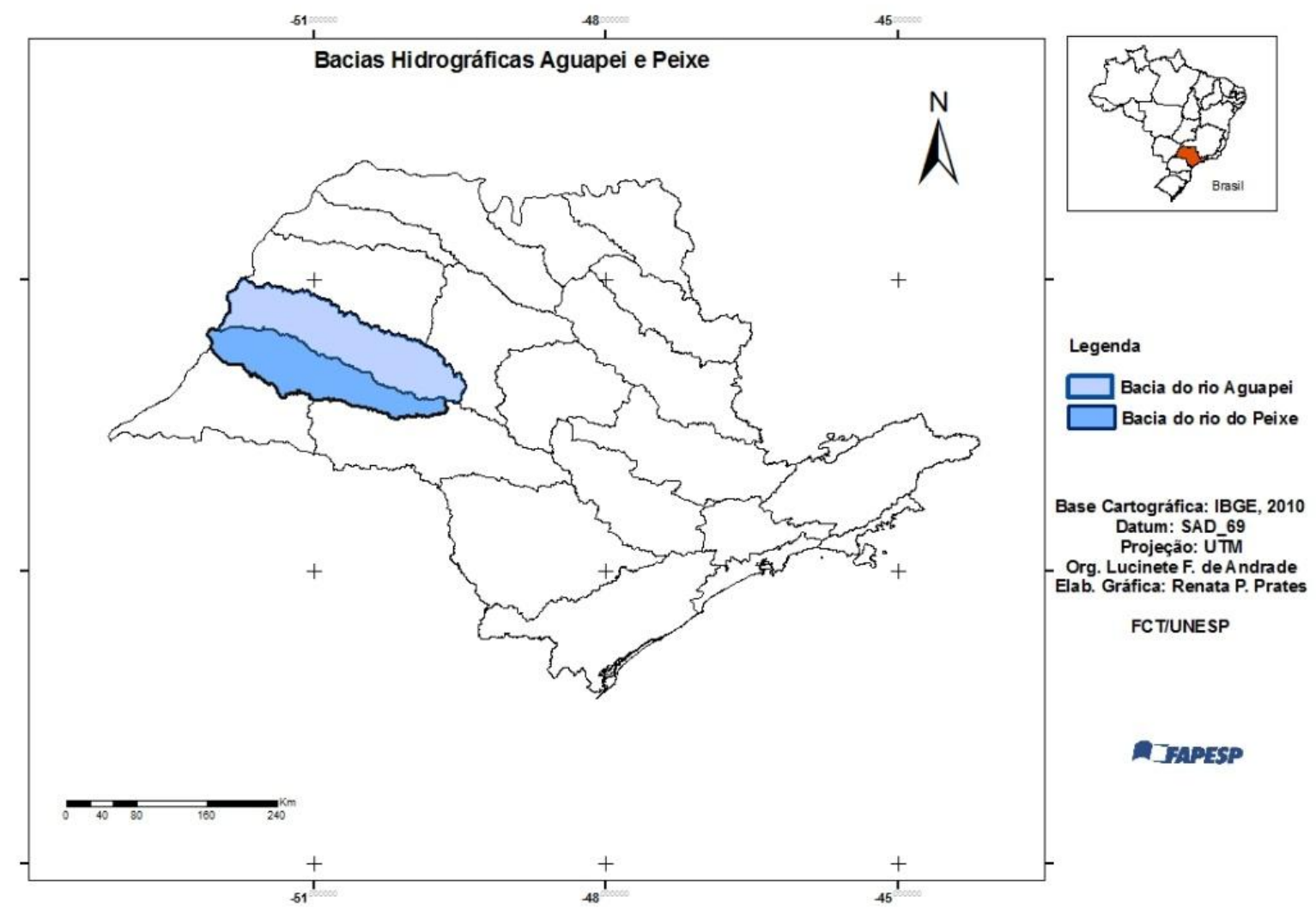

Figura 1 - Localização da área de estudo

Conforme Godoy (1999), as Bacias Hidrográficas dos Rios Aguapeí e Peixe estão situadas sobre três unidades do Grupo Bauru: Formação Marília a Leste, sobre a Formação Santo Anastácio e Formação Adamantina a Oeste, com predominância desta última.

Em relação à caracterização da Formação Adamantina, o Instituto florestal a define como uma área

[...] predominante ao longo das duas bacias e caracteriza-se pela uniformidade litológica. É formada por arenitos entre finos e médios, bem arredondados, com coloração arroxeada, com abundantes estratificações cruzadas de grande a médio porte, e presença local de cimentos e nódulos carbonáticos. Os arenitos são compostos basicamente por quartzo, feldspatos, calcedônia e opacos, 


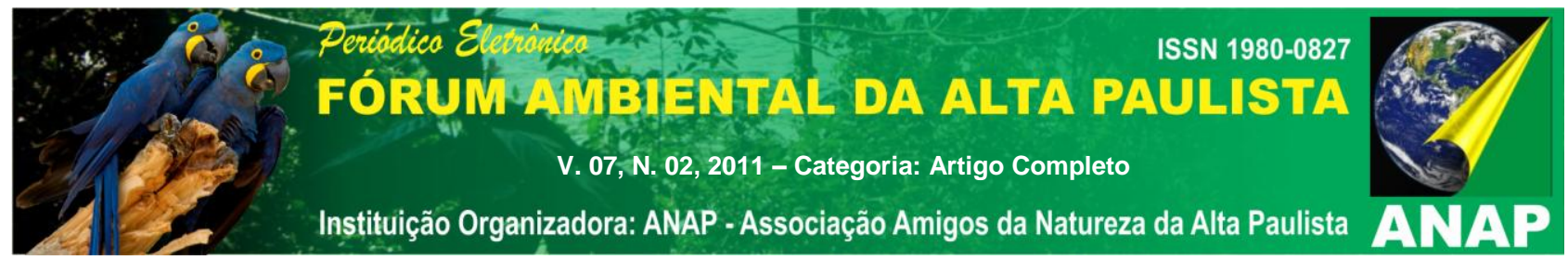

definindo-se tipo quartozos, ocasionalmente com caráter subarcosiano. (SÃO PAULO, 2006, p. 97).

Em termos Geomorfológicos, a área de estudo, contida na porção Oeste do Estado localiza-se no Planalto Ocidental Paulista, que abrange uma área de aproximadamente 50\% do Estado de São Paulo, partindo da província das Cuestas Arenítico - Basálticas até ao limite norte (rio Grande), oeste (rio Paraná) e sul (rio Paranapanema). De modo geral, predominam interflúvios sem orientação preferencial, com topos angulosos e achatados e vertentes ravinadas com perfis retilíneos. A drenagem é de média a alta densidade, com padrão dendrítico e vales fechados. (NUNES, FREITAS E PERE Z, 2007, p.16).

De acordo com SÃO PAULO (2011), a disponibilidade hídrica (superficial e subterrânea) nessa região hidrográfica, aproxima-se à média do Estado de São Paulo. Entretanto, o volume de água destinada às demandas outorgadas esteve entre os menores do Estado. Em relação à disponibilidade per capita, essa área foi considerada rica em água.

Tucci (2002), enfatiza que a variabilidade hidrológica é um processo estocástico no tempo e no espaço, variando de acordo com um conjunto de condições seja de clima como a precipitação, evapotranspiração, radiação solar, ou condições físicas como relevo, geologia, geomorfologia e solos e também pela cobertura vegetal e uso do solo, ou mesmo as ações antrópicas sobre o sistema fluvial.

O autor supracitado afirma ainda que em regiões de clima com estações bem definidas a identificação dos períodos hidrológicos é mais fácil do que onde as estações apresentam padrão de chuvas mais distribuídas ao longo do ano, neste caso há maior dificuldade para identificação dos períodos de cheia e estiagem. Para tal, utiliza-se a média mensal das vazões, que mostra a variabilidade dos meses ao longo do ano, através desta pode-se identificar períodos sazonais em uma dada bacia hidrográfica.

\subsection{Possíveis diagnósticos para o desvio das vazões médias nas bacias hidrográficas dos rios Aguapeí e Peixe}




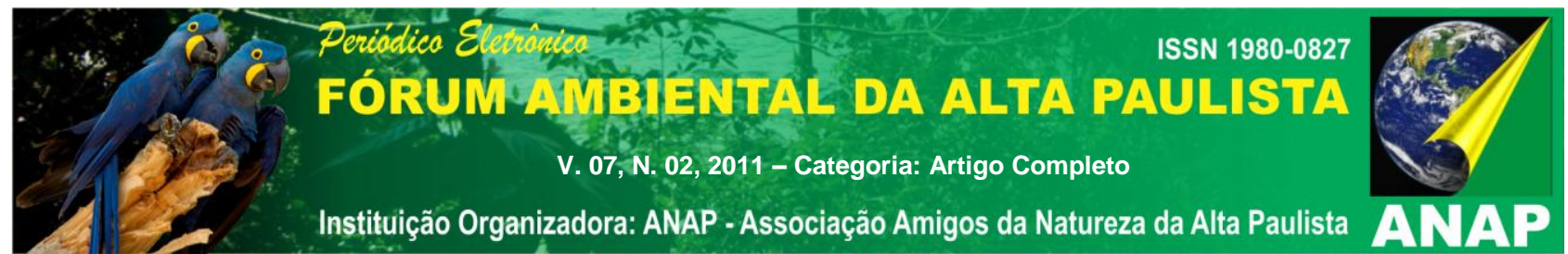

De acordo com o descrito na metodologia, foram identificados três possíveis períodos hidrológicos na série de dados das duas bacias hidrográficas. $\mathrm{Na}$ bacia hidrográfica do rio Aguapeí, os períodos hidrológicos identificados foram: um primeiro até o ano de 1971, o segundo entre 1972 e 1984 e o terceiro de 1985 a 2000 . A figura 2 demonstra de forma geral, o desvio médio da vazão na bacia hidrográfica do rio Aguapeí ao longo do período de monitoramento da estação fluviométrica Fazenda Bom Retiro, no município de Luisiana.

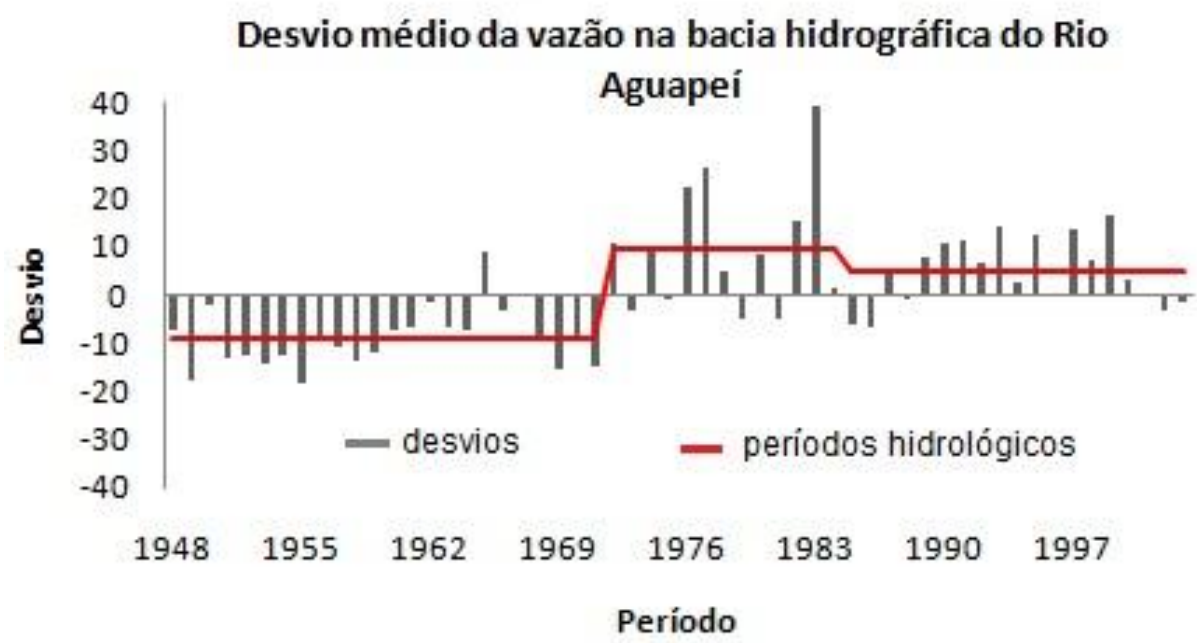

Figura 2. Desvio médio das vazões na bacia hidrográfica do rio Aguapeí, dados coletados da estação fluviométrica Fazenda Bom Retiro, município de Luisiana.

Percebe-se com clareza o predomínio de desvios negativos até o final da década de 1960, e desvios positivos, sobretudo, entre o início da década de 1970 até meados da década de 1980, quando os mesmos se apresentaram muito intensos, já num terceiro período hidrológico os desvios continuam positivos, porem não com a mesma intensidade do período anterior.

A figura 3 apresenta os desvios médios das vazões na bacia hidrográfica do rio do Peixe, é possível notar que, embora haja três períodos hidrológicos identificados, há menor amplitude na nos desvios médios das vazões, se comparado ao comportamento das vazões do rio Aguapeí. 

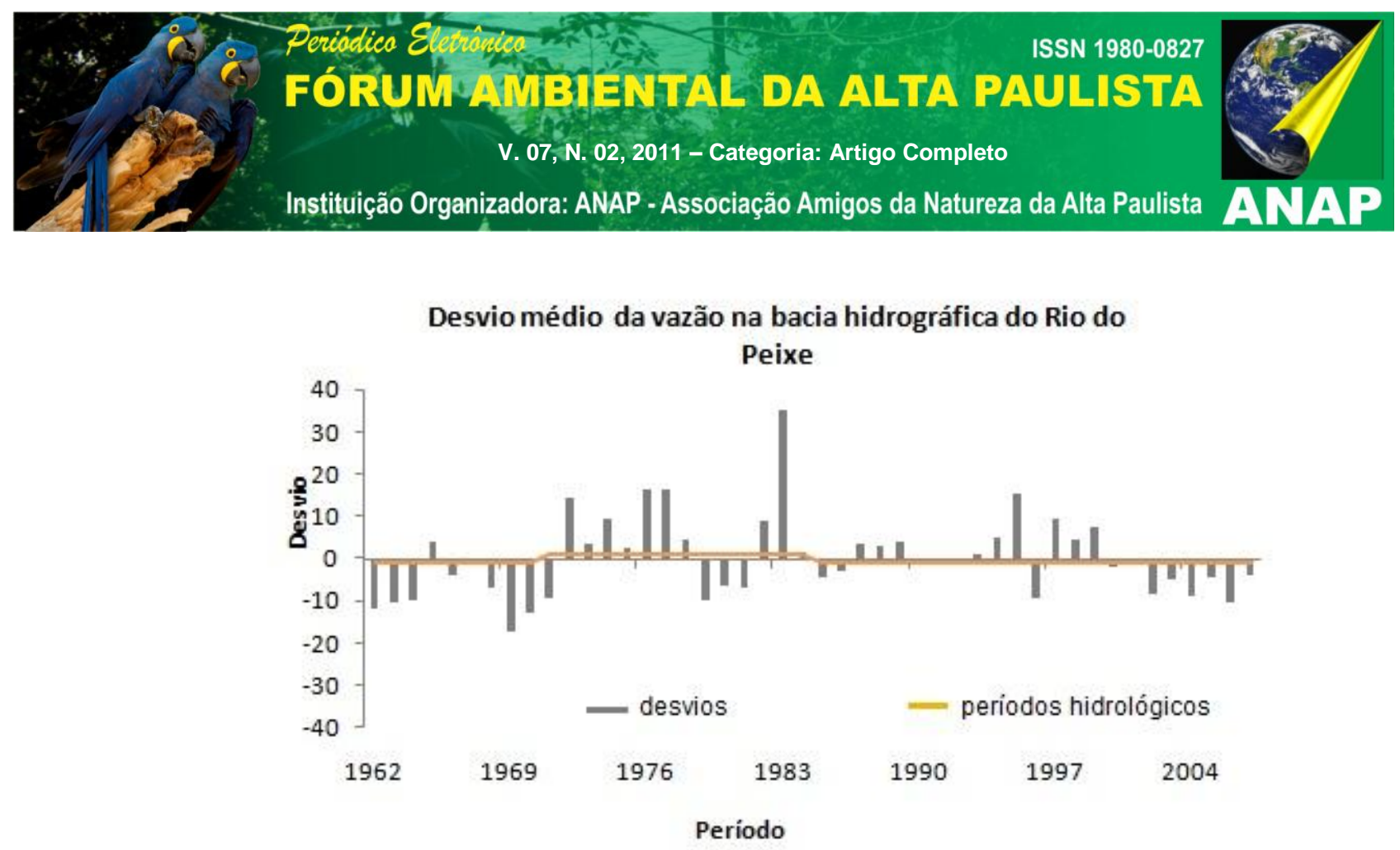

Figura 3. Desvio interanual das vazões médias na bacia hidrográfica do rio do Peixe, dados coletados da estação fluviométrica Estrada do Quatá, município de Tupã.

Nota-se que no primeiro período hidrológico, do início da série até aproximadamente 1971 e no terceiro período que compreende os anos posteriores a 1984, os desvios foram negativos, enquanto que no segundo período, entre 1972 e 1984, os desvios foram positivos demonstrando predomínio do ano de 1983.

Vários fatores de ordem natural ou antrópica podem influenciar tais variabilidades, ora podem ser atribuídas ao tipo de uso e ocupação dos solos na área e/ou à variabilidade dos ritmos climáticos, pois estes são normalmente causadores de mudanças em curto prazo.

Um fator de considerável impacto seria a variação do ritmo climático, que em escala regional é condicionado pela circulação secundária, pois de acordo com Zavatini (1992), a região que compreende o sul mato-grossense passando pelo oeste do Estado de São Paulo até Guaíra no Estado do Paraná é fortemente influenciada por sistemas de circulação secundária. Esta por sua vez altera os índices de umidade regional podendo ocasionar significativos níveis pluviométricos.

Azevedo et al. (2006), em estudo de caso, afirmam que os anos de 1982/83 e 1998, foram marcados por chuvas intensas, acarretando maiores índices de vazão na bacia do Rio Iguaçu no Estado do Paraná, tal fato foi atribuído à ocorrência do fenômeno El Niño. Considerando a influencia que este fenômeno possui sobre os climas regionais, 


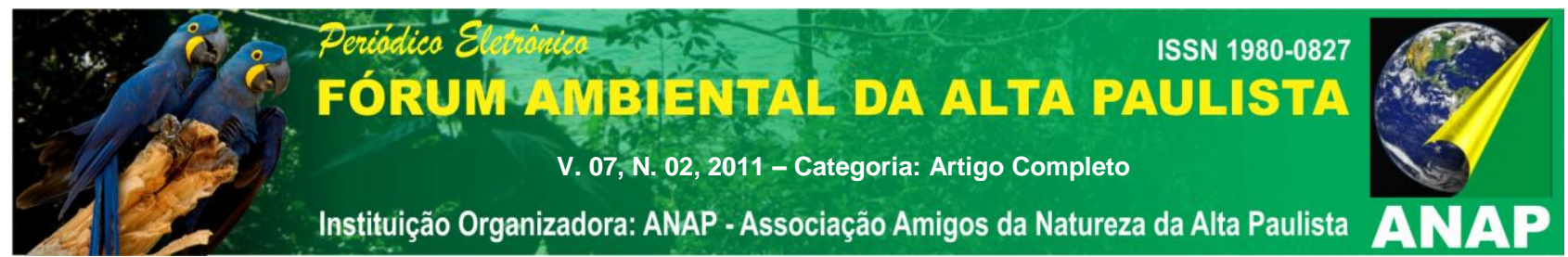

verifica-se que nas bacias hidrográficas dos rios Aguapeí e Peixe, sobretudo o ano de 1983 destacou-se por apresentar maior amplitude nos desvios da vazão média.

A tabela abaixo apresenta em valores os desvios já apresentados nas figuras acima para facilitar a compreensão da variação das vazões médias nas bacias hidrográficas dos rios Aguapeí e Peixe ao longo da série de monitoramento das estações que foram de 1948 a 2003 e de 1962 a 2007 respectivamente.

Tabela 1 - desvios das vazões médias nas bacias hidrográficas Aguapeí e Peixe

\begin{tabular}{l|l|l|l|c}
\hline $\begin{array}{l}\text { Bacias } \\
\text { Hidrográficas }\end{array}$ & $\begin{array}{l}\text { Desvios positivos } \\
\left(\mathbf{m}^{3} / \mathbf{s}\right)\end{array}$ & Ano & $\begin{array}{l}\text { Desvios negativos } \\
\left(\mathbf{m}^{3} / \mathbf{s}\right)\end{array}$ & Ano \\
\hline Rio Aguapeí & 39,16 & 1983 & $-18,24$ & 1955 \\
\hline & 34,95 & 1983 & $-17,50$ & 1969 \\
$\begin{array}{l}\text { Rio do Peixe } \\
\text { Fonte: ANA, SIGRH (2010) }\end{array}$ & &
\end{tabular}

A morfometria da bacia hidrográfica também deve ser considerada como relevante para o comportamento da vazão hidrológica, tratando-se do sistema de drenagem, visto que as bacias hidrográficas em estudo embora apresentem o mesmo padrão de drenagem, a área drenada na bacia do rio Aguapeí é maior do que a área de drenagem do Peixe. Desse modo a velocidade de escoamento varia de acordo com o padrão de drenagem e com o tamanho da bacia hidrográfica, não obstante a velocidade de escoamento seja determinada pelo relevo da bacia (Cunha e Guerra, 1995, p.98).

\section{CONCLUSÃO}

Este estudo tentou demonstrar que a variabilidade das vazões hidrológicas nas bacias hidrográficas analisadas podem ser influenciadas por inúmeros fatores, desde eventos climáticos e tipo de uso e ocupação e/ou sistema de drenagem, não eliminando também de outro fator de fundamental importância para o estudo do regime hidrológico que é a formação geológica e geomorfológica da área.

Em relação ao cerne deste trabalho considera-se que, as duas bacias hidrográficas em estudo, possuem algumas disparidades relativas à morfometria (tamanho da área de 


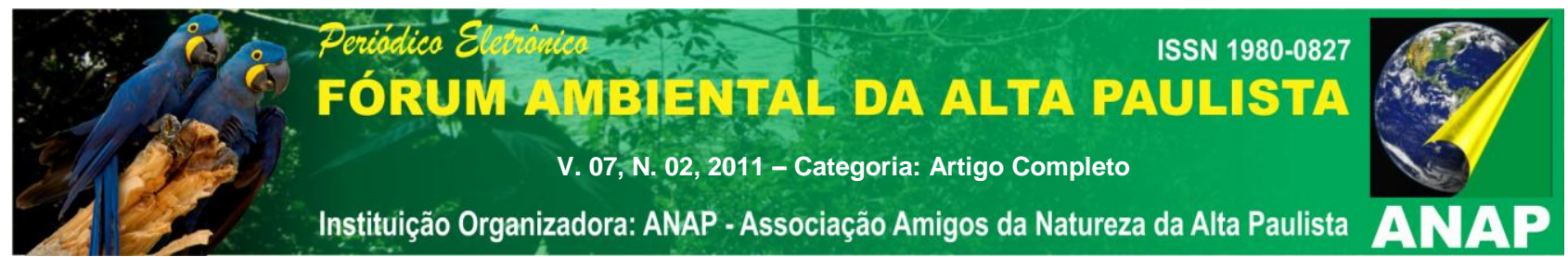

drenagem), este por si só, já pode ser considerado fator de relevância nas diferenças do comportamento hidrológico, conforme períodos hidrológicos identificados.

Ainda que, nas duas bacias estudadas possa haver também diferentes tipos de usos do solo, estes por sua vez, podem interferir nos regimes de chuvas de abrangência regional. Quanto aos fenômenos de maior abrangência como os ENOS, também não podem ser descartadas possibilidades, pois influenciam os climas regionais, acarretando mudanças eventos no regime de chuvas e estiagens, alterando, por conseguinte, 0 regime das vazões hidrológicas.

É importante ressaltar que este estudo é parte de uma pesquisa maior que envolve a avaliação do comportamento hidrológico dos rios Aguapeí e Peixe e para tanto, é avaliado a partir de dados hidrológicos disponibilizados pelas estações fluviométricas com série de histórica. Isto porque, acredita-se que o reconhecimento acerca da situação dos recursos hídricos, bem como o levantamento de inventário das estações fluviométricas seja de fundamental importância aos órgãos de gestão, uma vez que é iminente a implementação da política de cobrança pelo uso dos recursos hídricos nessa área.

\section{REFERÊNCIAS}

\section{Araujo, A. P. Dinâmica fluvial e regime hidrológico na bacia hidrográfica do rio}

Paranapanema. 2011. 151f. Dissertação (mestrado em Geografia). Presidente Prudente: Universidade Estadual Paulista. (em fase de publicação)

AZEVEDO, L. C., ANDRADE, A. R.; SOUZA, P.; NERY, J. T.; 2006. A influência do fenômeno El Niño na vazão da Bacia do Rio Iguaçu-PR. In: Revista Perspectiva Geográfica. Maringá, ano 1, nํ2, p 51-65, 2006

BRASIL. Ministério da Ciência e Tecnologia. SÃO PAULO (Estado). MOLION, L. C. B. Aquecimento global, El Niños, manchas solares, vulcões e oscilação Decadal do pacífico. In: Revista Climanálise, São Paulo, ano 3, número1, 2005.

CUNHA, Sandra B. e GUERRA, Antonio J. T. (Orgs.). Geomorfologia: Uma atualização de bases e conceitos. $2^{a}$ ed. Rio de Janeiro: Bertrand, 1995, p. 95-113 


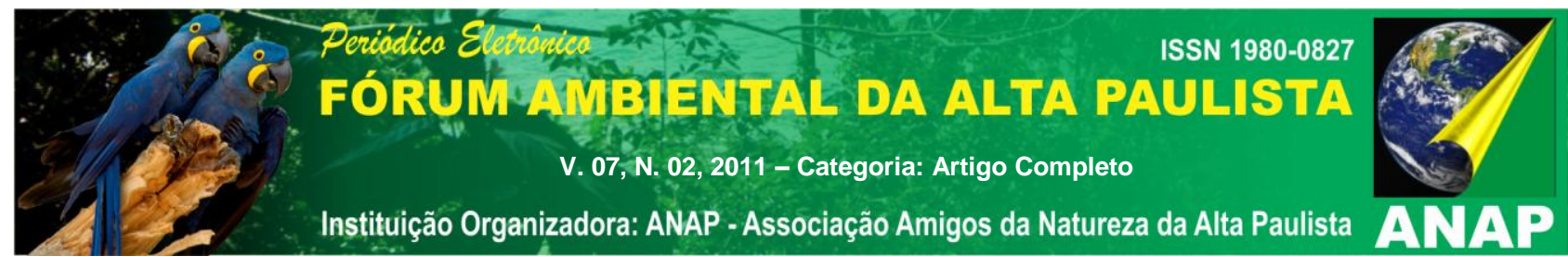

FERREIRA, J. H. D.; NERY, J. T. Relações de parâmetros meteorológicos associados com índice de oscilação sul. In: Boletim de Geografia. São Paulo, v. 17, p 103-114, 1999.

GODOY, M. C.T. Estudo hidrogeológico das zonas não saturada e saturada da formação Adamantina em Presidente Prudente - SP. 1999. 156 f. Tese (Doutorado em Geociências) - Instituto de Geociências, Universidade de São Paulo, São Paulo.

GUETTER, A. K.; Associação entre a vazão no Rio Paraná e o El. Niño. In: X CONGRESSO BRASILEIRO DE METEOROLOGIA, BRASILIA, 1998: Anais X Congresso Brasileiro de Meteorologia, p. 1-5. Disponível em http://www.cbmet.com/cbm-files/13190ea83ca14b96b8ee9af8e69840ab60.pdf acessado em 30 de aug. de 2011.

NUNES, J. O. R.; FREITAS, R.; PEREZ, I. U. Mapeamento geomorfológico no município de Presidente Prudente-SP. Volume 1, FAPESP, 2007, p.16

POFF, H.L., ALLAN, D., BAIN, M.B., KARR, J.R., PRESTEGAARD, K.L., RICHTER, B.D., SPARKS, R.E., \& STROMBERG, J.C., 1997. The natural flow regime: a paradigm for river conservation and restoration. Bioscience, vol. 47, n. 11. p. 769-784.

ROCHA, P. C.; Dinâmica dos canais no sistema rio-planície fluvial do alto rio Paraná, nas proximidades de Porto Rico-PR. 2002. 171 f. Tese (Doutorado em Ecologia de Ambientes Aquáticos Continentais) - Universidade Estadual de Maringá, Maringá.

ROCHA, P. C.; O regime de fluxo dos Rios Aguapeí e Peixe, Bacia do alto Paraná/Brasil: alterações e formas de impacto. In: XII ENCUENTRO DE GEÓGRAFOS DE AMÉRICA LATINA, 12, 2009, Montevideo: Anais XII Encuentro de Geógrafos de América Latina: Universidad de la República, 2009. p. 1-12.

SANT'ANNA NETO, J. L. As chuvas no Estado de São Paulo: Contribuição ao estudo da variabilidade e tendência da pluviosidade na perspectiva da análise geográfica. 


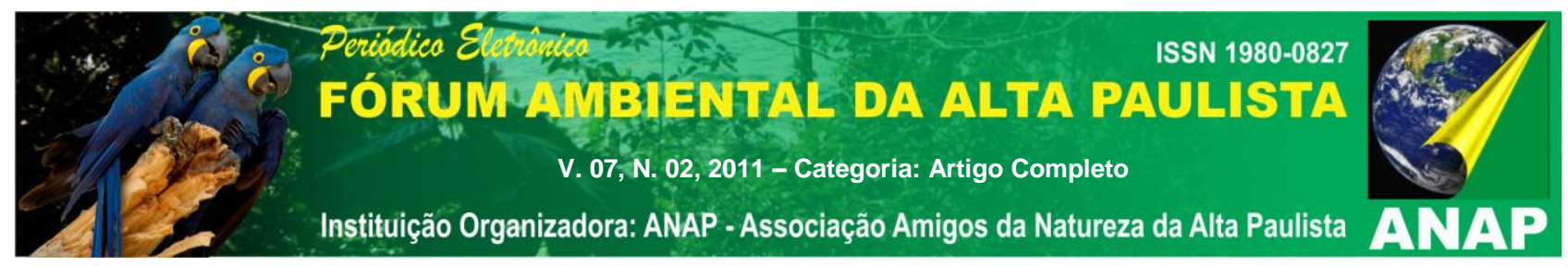

1995, 202 f. Tese (Doutorado em Geografia) - Faculdade de Filosofia, Letras e Ciências Humanas, Universidade de São Paulo, São Paulo.

SÃO PAULO. Secretaria do meio ambiente. Plano de manejo do Parque Estadual Morro do Diabo - Plano de Manejo. Coord. Editorial Helder H. Faria e Andréa S. Pires. Editora Viena. São Paulo, 2006. p. 39-40.

SOUZA, C. G. Análise dos episódios climáticos extremos no oeste paulista a partir das noticias veiculadas pela imprensa local. 2005, Disponível em: <

http://www4.fct.unesp.br/grupos/gaia/publicacoes/monografias/monografia camila grosso de souza\%5B1\%5D.pdf> acesso em: 01 de set 2011.

TUCCI, Carlos E. M. Regionalização de vazões. Rio Grande do Sul: Ed.

Universidade/UFRGS, 2002. p.14

TUCCI, Carlos E. M. Vazão Máxima e hidrograma de projetos. In: Hidrologia:

Ciência e aplicação. $4^{a}$ Ed. Porto Alegre: Editora da UFRGS/ABRH, 2007, p. 527-539.

TUNDISI, J. Galizia. Água no século XXI: Enfrentamento e escassez. - São Paulo: Rima, IIE, 2003, p. 139-156.

VILLELA, S. M.; MATTOS, A.; Hidrologia Aplicada. São Paulo: McGraw-Hill, 1975.

ZAVATINI, J.A.; A circulação secundária e a pluviosidade no Mato Grosso do Sul. In: XVI Congresso Brasileiro de Meteorologia. Anais XVI Congresso Brasileiro de Meteorologia. São Paulo, 1992, p. 257-260. 


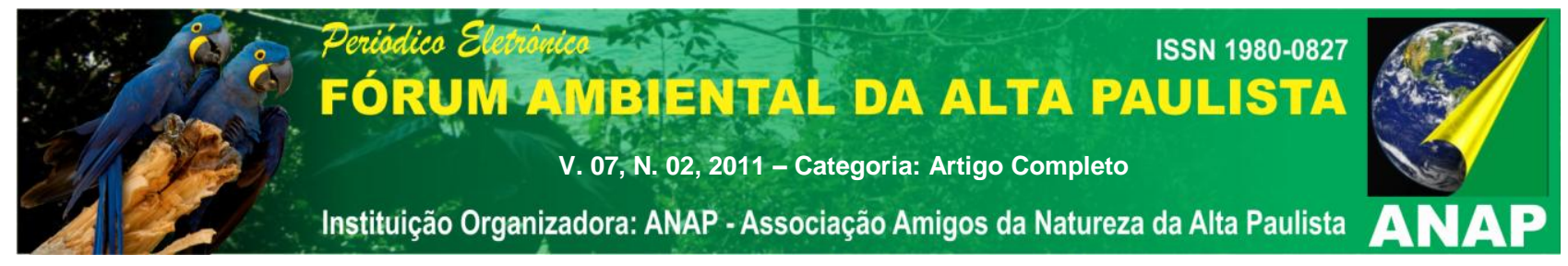

